\title{
Prevalence of genetic variants of keratins 8 and 18 in patients with drug-induced liver injury
}

\author{
Valentyn Usachov ${ }^{1,5}$, Thomas J. Urban², Robert J. Fontana ${ }^{3}$, Annika Gross ${ }^{1}$, Sapna lyer ${ }^{4}$, M. Bishr Omary ${ }^{4}$,
} Pavel Strnad ${ }^{1 *}$ and on behalf of the Drug-Induced Liver Injury Network

\begin{abstract}
Background: Keratin 8 and 18 (K8/K18) cytoskeletal proteins protect hepatocytes from undergoing apoptosis and their mutations predispose to adverse outcomes in acute liver failure (ALF). All known K8/K18 variants occur at relatively non-conserved residues and do not cause keratin cytoskeleton reorganization, whereas epidermal keratinconserved residue mutations disrupt the keratin cytoskeleton and cause severe skin disease. The aim of our study was to identify keratin variants in idiosyncratic drug-induced liver injury (DILI).
\end{abstract}

Methods: Genomic DNA was isolated from 800 patients enrolled in an ongoing US multicenter study, with DILI attributed to a wide range of drugs. Specific K8/K18 exonic regions were PCR-amplified and screened by denaturing HPLC followed by DNA sequencing. The functional impact of keratin variants was assessed using cell transfection and immune staining.

Results: Heterozygous and compound amino acid-altering K8/K18 variants were identified in 86 DILI patients and non-coding variants in 15 subjects. Five novel amino acid-altering (K8 Lys393Arg, K8 Ala351Val, K8 Ala358Val, K8 Ile346Val, K18 Asp89His) and two non-coding variants were observed. Several variants segregated with specific ethnic backgrounds but were found at similar frequencies in DILI subjects and ethnically matched population controls. Notably, variants in highly conserved residues of K8 Lys393Arg (ezetimibe/simvastatin-related) and K18 Asp89His (isoniazid-related) were found in patients with fatal DILI. These novel variants also led to keratin network disruption in transfected cells.

Conclusions: Novel K8/K18 cytoskeleton-disrupting variants were identified in two patients and segregated with fatal DILI. Other non-cytoskeleton-disrupting keratin variants did not preferentially associate with DILI.

Keywords: Intermediate filaments, Mutation, Drug-induced liver injury, DILI

\section{Background}

Keratins (Ks) represent a subgroup of intermediate filaments (IFs) found mainly in epithelial tissues [1-3]. As for all IFs, they display a tripartite structure containing a conserved $\alpha$-helical central rod domain that is flanked by a less conserved $\mathrm{N}$-terminal head and $\mathrm{C}$-terminal tail domains $[4,5]$. Keratins are further subdivided into the relatively acidic type I (including $\mathrm{K} 9-\mathrm{K} 28$ and $\mathrm{K} 31-\mathrm{K} 40$ ) and relatively basic type II IFs (including $\mathrm{K} 1-\mathrm{K} 8$ and K71-K86) that associate as obligate non-covalent heteropolymers [6, 7]. Consequently, every cell type

\footnotetext{
* Correspondence: pstrnad@ukaachen.de

'Department of Internal Medicine III and IZKF, University Hospital Aachen,

RWTH Aachen, Pauwelsstrasse 30, D-52074 Aachen, Germany

Full list of author information is available at the end of the article
}

contains a characteristic type I-II expression pattern $[1,7]$. For example, $\mathrm{K} 1 / \mathrm{K} 10$ and $\mathrm{K} 5 / \mathrm{K} 14$ are the major keratins of suprabasal and basal keratinocytes, respectively, while $\mathrm{K} 8 / \mathrm{K} 18 / \mathrm{K} 19 / \mathrm{K} 20$ are the keratins found in simple type glandular epithelia [2, 8]. Adult hepatocytes are unique in that they only contain $\mathrm{K} 8 / \mathrm{K} 18$, while most other cell types display a more complex keratin expression pattern $[8,9]$. It is this heteropolymeric keratin-keratin association that accounts for the amino acid position-selective dominant negative effect of heterozygous keratin mutations in human disease.

Keratins are established cytoprotective proteins $[10,11]$ and keratin mutations lead or predispose to the development of $>60$ distinct human diseases $[2,12,13]$ that are faithfully reproduced in transgenic animals models $[8,14]$. 
In mouse liver, mutations or loss of $\mathrm{K} 8 / \mathrm{K} 18$ cause a mild phenotype under basal conditions, but predispose to significant injury from a variety of stresses including apoptotic, metabolic, oxidative and drug-induced [11, 15-17]. Human association studies have identified keratin variants to be overrepresented in patients with end-stage liver disease, acute liver failure (ALF), chronic hepatitis $C$ virus infection or primary biliary cirrhosis, and to predispose to adverse clinical outcomes $[8,18,19]$.

Human studies also revealed marked differences in ethnic distribution of keratin variants. For example, K8 G62C and $\mathrm{K} 8 \mathrm{R} 341 \mathrm{H}$ were the most abundant amino acid substitutions in Caucasians, while AfricanAmerican (AA) subjects displayed high frequencies of $\mathrm{K} 8 \mathrm{~A} 333 \mathrm{~A}$ and G434S variants [19]. Importantly, K8/ K18 variants were found in the less conserved protein regions and did not affect keratin organization under basal conditions, while disease-causing mutations in epidermal keratins cluster in the most conserved subdomains at the amino and carboxyl regions of the rod domain, and often result in keratin network breakdown $[2,8,14,20]$. For example, K14 R125C leads to the most severe Dowling Meara form of epidermolysis bullosa simplex (EBS) [14]. The homologous K18 alteration (K18 R90C) that was engineered in transgenic animals results in a disruption of filamentous hepatocellular keratin network, mild chronic hepatitis and distinct susceptibility to various hepatotoxic stresses $[8,15]$.

Given the murine data suggesting keratin mutationassociated susceptibility to chemical hepatotoxicity and human studies linking K8/K18 variants to acetaminophen hepatotoxicity [19], we hypothesized that K8/K18 variants may contribute to the susceptibility to human idiosyncratic drug-induced liver injury (DILI) that is a prominent cause of ALF [21, 22]. DILI is also a major adverse event leading to termination of clinical drug development programs [23]. Several previous studies suggested that DILI has a genetic component with variants in human leukocyte antigens and drug metabolizing enzymes increasing risk for development of DILI [22, 24]. We tested our hypothesis by analyzing 800 consecutive DILI subjects enrolled in the ongoing DILI Network (DILIN) study and identified several novel K8/K18 variants.

\section{Methods}

\section{Study participants}

Between August 2004 and April 2009, 808 subjects were recruited from eight US clinical sites participating in the DILIN. Details of the inclusion/exclusion criteria were previously described [25]. DILI causality assessment and severity was based on consensus of a panel of experienced hepatologists [25]. The cases were subdivided into hepatocellular, cholestatic or mixed injury pattern based on the R-value $[25,26]$. All participants provided written informed consent, which included collection of DNA for genetic association studies, and the study was approved by the local institutional review boards of the participating centers (see list in the Acknowledgements section). For control data of keratin variants in Caucasian and African-American subjects, we used the Exome Sequencing Project database available through the Exome Variant Server [27] whereas the 1000 Genomes project data [28] were employed for Hispanic and Asian controls.

\section{Genetic analysis}

Genomic DNA was obtained from EDTA-anticoagulated peripheral blood with a DNeasy Tissue Kit (Qiagen, Valencia, CA, USA). The mutational K8/K18 hotspots (K8 exons 1, 6, 8 (corresponding to amino acids 1-108, 328-400, 421-483); K18 exon 1 (corresponding to amino acids 1-139) and their adjacent exon-intron boundaries) were PCR-amplified using AmpliTaq Gold ${ }^{\circ}$ DNA Polymerase (Applied Biosystems, Foster City, CA, USA) and previously described primers [29]. The selection of these hotspots is based on more than 2,000 human subjects in whom the entire K8/K18 exonic regions were analyzed [17-19, 29, 30]. All PCR products were pre-screened with the $\mathrm{WAVE}^{\circ}$ denaturing HPLC system (Transgenomic, Omaha, NE, USA). Specimens with an abnormal elution peak were confirmed in an independent PCR analysis, purified and subjected to bidirectional DNA sequencing. Annotation of coding K8/K18 variants was made with the mRNA sequences NM_002273.3/NM_000224.2, while the sequences M34482.1/AF179904.1 were used for noncoding changes. The conservation of the observed K8/K18 variants was analyzed using the following sequences: K8: NP_002264.1 (human), NP_112447.2 (mouse), NP_ 001028782.1 (cow), NP_001080525.1 (frog), NP_956374.1 (zebrafish); K1 (NP_006112.3), K2 (NP_000414.2), K3 (NP_476429.2), K4 (NP_002263.2), K5 (NP_000415.2), K6a (NP_005545.1), K7 (NP_005547.3); K18: NP_000215.1 (human), NP_034794.2 (mouse), NP_001179024.1 (cow), NP_001089734.1 (frog), NP_848524.1 (zebrafish); K9 (NP_000217.2), K10 (NP_000412.3), K12 (NP_000214.1), K13 (NP_705694.2), K14 (NP_000517.2), K15 (NP_ 002266.2), K16 (NP_005548.2), K17 (NP_000413.1), K19 (NP_002267.2), K20 (NP_061883.1). Given that eight samples were not reliably amplified, 800 samples were included in the final analysis.

\section{Statistical analysis}

The Fisher's exact test was used to determine nonrandom associations between two variables, and $P$ values less than 0.05 were considered statistically significant.

\section{Cell culture experiments}

To study the biological significance of novel K8/K18 variants, human $\mathrm{K} 8$ and $\mathrm{K} 18$ cDNA inserted in the 
Table 1 Characteristics of the DILI cohort

\begin{tabular}{|c|c|c|c|c|c|}
\hline \multirow[t]{2}{*}{ Gender } & \multirow{2}{*}{$\begin{array}{l}\text { Male } \\
335(41.9)\end{array}$} & \multirow{2}{*}{$\begin{array}{l}\text { Female } \\
465(58.1)\end{array}$} & \multicolumn{3}{|l|}{ Total } \\
\hline & & & $800(100)$ & & \\
\hline \multirow[t]{2}{*}{ Ethnicity/race } & AA & Asian & Caucasian & Hispanic & Other \\
\hline & 87 (10.9) & $25(3.1)$ & $577(72.1)$ & $88(11.0)$ & $23(2.9)$ \\
\hline \multirow[t]{2}{*}{ Causality $^{a}$} & Definitive & Very likely & Probable & Possible & Unlikely \\
\hline & $190(23.8)$ & $312(39.0)$ & $148(18.5)$ & $110(13.8)$ & $39(4.9)$ \\
\hline \multirow[t]{2}{*}{ Injury type } & Hepatocellular & Cholestatic & Mixed & & \\
\hline & $438(54.8)$ & $198(24.7)$ & $164(20.5)$ & & \\
\hline \multirow[t]{2}{*}{ Severity } & Fatal (5) & Severe (4) & Mod hosp (3) & $\operatorname{Mod}(2)$ & Mild (1) \\
\hline & $71(8.9)$ & $144(18.0)$ & $221(27.6)$ & $176(22.0)$ & 188 (23.5) \\
\hline
\end{tabular}

Absolute numbers are shown followed by percentages in brackets. ${ }^{a}$ Causality score was unknown in one patient. AA, African-American; DILI, drug-induced liver injury; Mod, moderate non-hospitalized; Mod hosp, moderate hospitalized

Table 2 Distribution of keratin variants in DILI patients stratified by subject race/ethnicity

\begin{tabular}{|c|c|c|c|c|c|c|c|c|}
\hline \multirow[b]{4}{*}{ Nucleotide } & \multirow[b]{4}{*}{ Variant } & \multirow[b]{4}{*}{ dbSNP ID } & \multicolumn{6}{|c|}{ Race/ethnicity } \\
\hline & & & $\overline{A A}$ & Asian & Caucasian & Hispanic & Other & Total \\
\hline & & & \# (\%) & \# (\%) & \# (\%) & \# (\%) & \# (\%) & \# (\%) \\
\hline & & & 87 (10.9) & $25(3.1)$ & $577(72.1)$ & $88(11.0)$ & $23(2.9)$ & $800(100)$ \\
\hline $160 \mathrm{~T}>\mathrm{C}$ & K8 Y54H & rs57749775 & 0 & 0 & 0 & $1(1.1)$ & 0 & $1(0.1)$ \\
\hline $184 \mathrm{G}>\mathrm{T}$ & K8 G62C & rs11554495 & 0 & 0 & $10(1.7)^{c}$ & 0 & $1(4.3)$ & $11(1.4)$ \\
\hline $187 A>G$ & K8 I63V & rs59536457 & 0 & 0 & $8(1.4)$ & 0 & $1(4.3)$ & $9(1.1)$ \\
\hline IVS1+30G $>A^{e}$ & K8 Intr & - & 0 & 0 & $1(0.2)$ & 0 & 0 & $1(0.1)$ \\
\hline $999 \mathrm{C}>\mathrm{T}$ & K8 A333A & rs7750 & $13(14.9)^{\mathrm{a}}$ & 0 & 0 & $2(2.3)$ & 0 & $15(1.9)$ \\
\hline $1022 \mathrm{G}>\mathrm{A}$ & K8 R341H & rs57422427 & $1(1.1)^{\mathrm{b}}$ & $1(4.0)$ & $27(4.7)^{c}$ & $9(10.2)$ & $2(8.7)$ & $40(5.0)$ \\
\hline $1036 \mathrm{~A}>\mathrm{G}^{\mathrm{e}}$ & K8 I346V & - & 0 & 0 & $1(0.2)^{d}$ & 0 & 0 & $1(0.1)$ \\
\hline $1052 C>T^{e}$ & K8 A351V & - & 0 & 0 & $1(0.2)$ & 0 & 0 & $1(0.1)$ \\
\hline $1073 C>T^{e}$ & K8 A358V & - & 0 & 0 & $1(0.2)$ & 0 & 0 & $1(0.1)$ \\
\hline $1138 G>A$ & K8 V380I & rs56997521 & 0 & 0 & $3(0.5)$ & 0 & 0 & $3(0.4)$ \\
\hline $1178 \mathrm{~A}>\mathrm{G}^{\mathrm{e}}$ & K8 K393R & - & 0 & 0 & $1(0.2)$ & 0 & 0 & $1(0.1)$ \\
\hline IVS6+46A>T & K8 Intr & rs189690662 & 0 & 0 & $9(1.6)^{d}$ & 0 & $1(4.3)$ & $10(1.3)$ \\
\hline $1300 G>A$ & K8 G434S & rs58573614 & $10(11.5)^{\mathrm{a}}$ & 0 & 0 & 0 & 0 & $10(1.3)$ \\
\hline $1383 G>T^{e}$ & K8 V461V & - & 0 & $1(4.0)$ & 0 & 0 & 0 & $1(0.1)$ \\
\hline $1438 \mathrm{G}>\mathrm{A}$ & K8 V480I & rs61730606 & $4(4.6)$ & 0 & $3(0.5)$ & 0 & 0 & $7(0.9)$ \\
\hline IVS8+8C >T & K8 Intr & rs201942002 & 0 & 0 & 0 & $1(1.1)$ & 0 & $1(0.1)$ \\
\hline IVS8+38G>A & K8 Intr & rs267607663 & $1(1.1)$ & 0 & 0 & 0 & 0 & $1(0.1)$ \\
\hline IVS8+27del9nt ${ }^{\mathrm{e}}$ & K8 Intr & - & 0 & 0 & $1(0.2)$ & 0 & 0 & $1(0.1)$ \\
\hline $\mathrm{K} 18-11 \mathrm{C}>\mathrm{T}$ & K18 Intr & - & $1(1.1)^{\mathrm{b}}$ & 0 & 0 & 0 & 0 & $1(0.1)$ \\
\hline K18 $\Delta 65-72$ & K18 Deletion & rs267607417 & 0 & 0 & 0 & $1(1.1)$ & 0 & $1(0.1)$ \\
\hline $265 G>C^{e}$ & K18 D89H & - & 0 & $1(4.0)$ & 0 & 0 & 0 & $1(0.1)$ \\
\hline \# (\%) patients with amino acid-altering variants & & & $15(17.2)$ & $2(8.0)$ & $54(9.4)$ & $11(12.5)$ & $4(17.4)$ & $86(10.8)$ \\
\hline \# (\%) patients with intronic variants & & & $2(2.3)$ & 0 & $11(1.9)$ & $1(1.1)$ & $1(4.3)$ & $15(1.9)$ \\
\hline
\end{tabular}


pcDNA3.1 vector was modified with the QuikChange ${ }^{\oplus}$ Site-Directed Mutagenesis Kit (Stratagene, Santa Clara, CA, USA) and specific primers (hK8-I346V-F ctggga gagctggccgttaaggatgccaacg, hK8-I346V-R cgttggcatccttaa cggccagctctccacg; hK8-A351V-F cattaaggatgccaacgtcaag ttgtccgagctgg, hK8-A351V-R ccagctcggacaacttgacgttggca tccttaatg; hK8-A358V-F cgagctggaggtcgcctgcagc, hK8A358V-R gctgcagggcgacctccagctcg; hK8-K393R-F cgcca cctacaggaggctgctggaggg, hK8-K393R-R cctccagcagcctcc tgtaggtggcg; hK18-D89H-F gcaaagcctgaaccaccgctggcctc,
hK18-D89H-R gaggccaggcggtggttcaggctttgc). The resulting constructs were verified by DNA sequencing. For immunofluorescence staining, NIH 3T3 cells (CRL-1658; American Type Culture Collection) were grown in DMEM medium (Gibco, Life Technologies $\mathrm{GmbH}$, Darmstadt, Germany) supplemented with 10 \% FCS, $1 \%$ penicillin-streptomycin and $1 \%$ L-glutamine, and then transfected with equal amounts of K8 or K18 variant cDNA together with an equal amount of non-mutated partner keratin (K18 or K8) cDNA using Lipofectamine

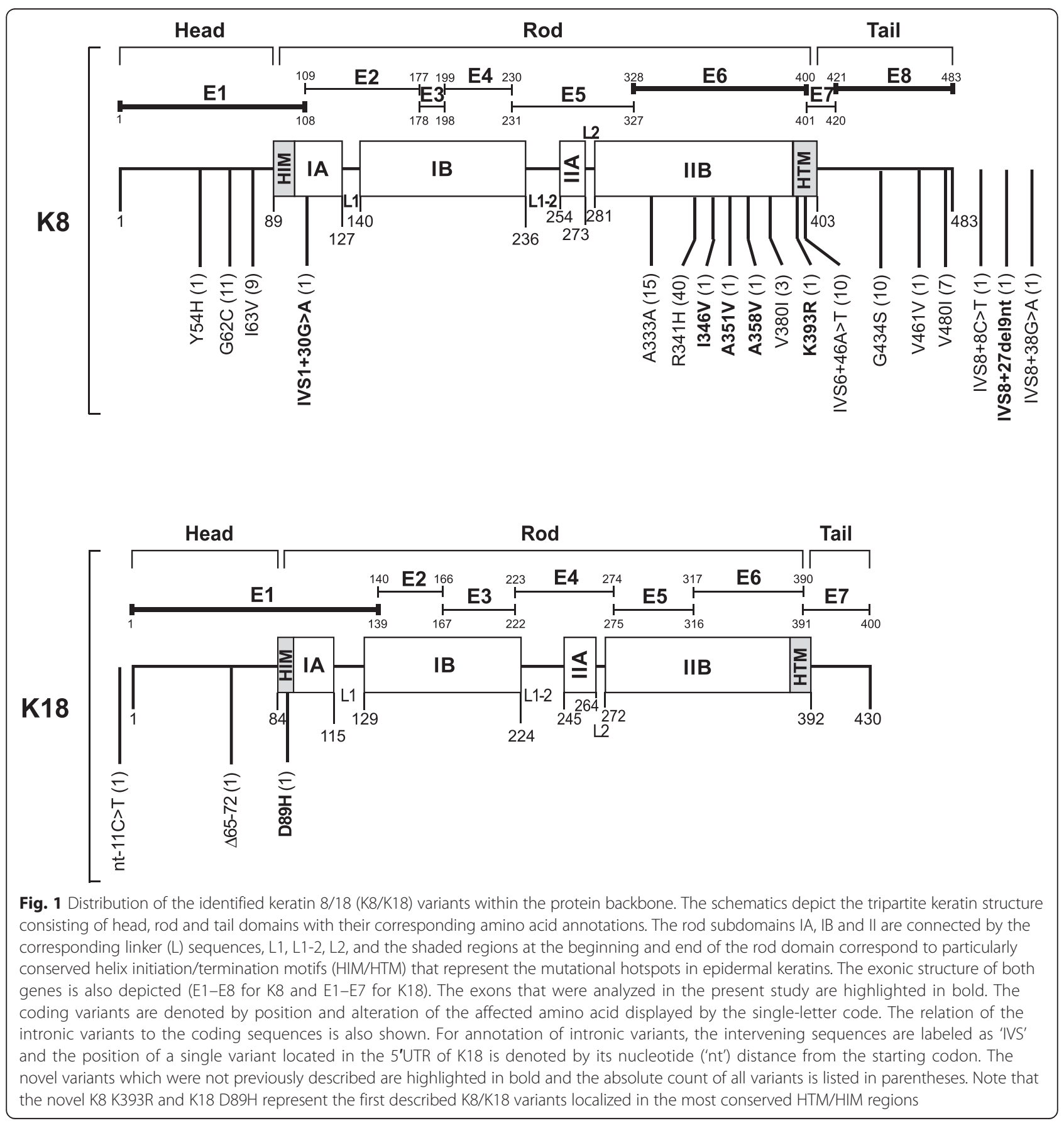


2000 (Invitrogen, Life Technologies GmbH, Darmstadt, Germany). Transfection of wild-type K8/K18 was used as control. Transfected cells were fixed with precooled $-20{ }^{\circ} \mathrm{C}$ methanol $(3 \mathrm{~min}$ ) and acetone (15 s) after 24 hours, washed in PBS, and incubated with the anti-K18 antibody Ks 18.04 (Progen Biotechnik GmbH, Heidelberg, Germany) [31]. After washing and exposure to the secondary antibody, the glass slides were mounted in ProLong ${ }^{\oplus}$ Gold antifade reagent with DAPI mounting medium (Life Technologies Corporation, Eugene, OR, USA). To quantify the percentage of disrupted cells, all transfections were performed in triplicate and at least 100 cells were scored in each case. Cells were characterized as having normal-appearing or disrupted cytoskeletal keratin network. Coomassie staining for total protein lysates of transient transfected cells has shown equal levels of proteins. Of note, the transfection efficiency was similar in all subgroups and ranged between 50-70\%.

\section{Results}

To address the importance of $\mathrm{K} 8 / \mathrm{K} 18$ variants in DILI, 800 well characterized DILI subjects were analyzed. Of the examined subjects, $72 \%$ were Caucasians, while Hispanics and African-Americans each constituted $11 \%$ of the study cohort (Table 1 ). In $63 \%$ of patients, DILI was deemed to be very likely or definite, while $<5 \%$ were scored as unlikely. Nearly $55 \%$ of subjects had hepatocellular injury at presentation, while $25 \%$ and $20 \%$ displayed a cholestatic and mixed damage pattern, respectively. Fatal DILI was recorded in $9 \%$ of patients and $55 \%$ of participants required hospitalization due to their liver injury (Table 1).

The analysis of $\mathrm{K} 8 / \mathrm{K} 18$ mutational hotspots revealed heterozygous exonic and intronic $\mathrm{K} 8 / \mathrm{K} 18$ variants in $101(12.6 \%)$ and 15 (1.9\%) patients, respectively (Table 2). Amino acid-altering variants were found in 86 subjects (10.8\%; Table 2). K8 R341H constituted the most frequent amino acid-altering variant found in 40 subjects (5 \%; Fig. 1) and was particularly common among Hispanics (9/88, $10.2 \%$; Table 2). On the other hand, K8 A333A (13/87, $14.9 \%)$ and K8 G434S (10/87, $11.5 \%$ ) variants were the most frequent variants among African-Americans and the latter greatly contributed to the fact that this ethnicity displayed a high percentage of amino acid-altering variants (15/87, $17.2 \%)$. K8 IVS6+46A $>\mathrm{T}$ represented the most common intronic variant that was seen in ten patients (1.3 \%; Fig. 1). We also detected eight novel and hitherto undescribed variants including five amino acid-altering (K8 K393R, K8 A351V, K8 A358V, K8 I346V, K18 D89H; Fig. 1; Additional file 1: Figure S1). Four patients harbored compound heterozygous variants ( $\mathrm{K} 8 \mathrm{G} 62 \mathrm{C}+\mathrm{R} 341 \mathrm{H}, \mathrm{K} 8 \mathrm{R} 341 \mathrm{H}+\mathrm{K} 18$ $11 \mathrm{C}>\mathrm{T}$, K8 A333A+G434S, K8 I346V+IVS6+46A>T; Table 2).

Table 3 Distribution of selected keratin variants in the DILI and population control groups by subgroup

\begin{tabular}{|c|c|c|c|c|c|c|c|c|c|c|}
\hline & Subgroup (\#) & & K8 G62C & K8 I63V & K8 A333A & K8 R341H & K8 V380I & K8 G434S & K8 V480I & Total $^{a}$ \\
\hline & & $\#$ & $11 / 800$ & $9 / 800$ & $15 / 800$ & $40 / 800$ & $3 / 800$ & $10 / 800$ & $7 / 800$ & $86 / 800$ \\
\hline & & $\%$ & 1.4 & 1.1 & 1.9 & 5.0 & 0.4 & 1.3 & 0.9 & 10.8 \\
\hline \multirow[t]{8}{*}{ DILI } & Caucasian (577) & $\#$ & $10^{\mathrm{b}}$ & 8 & 0 & $27^{b}$ & 3 & 0 & 3 & 54 \\
\hline & & $\%$ & 1.7 & 1.4 & 0 & 4.7 & 0.5 & 0 & 0.5 & 9.4 \\
\hline & African-American (87) & $\#$ & 0 & 0 & $13^{c}$ & 1 & 0 & $10^{c}$ & 4 & 15 \\
\hline & & $\%$ & 0 & 0 & 14.9 & 1.2 & 0 & 11.5 & 4.6 & 17.2 \\
\hline & Hispanic (88) & $\#$ & 0 & 0 & 2 & 9 & 0 & 0 & 0 & 11 \\
\hline & & $\%$ & 0 & 0 & 2.3 & 10.2 & 0 & 0 & 0 & 12.5 \\
\hline & Asian (25) & \# & 0 & 0 & 0 & 1 & 0 & 0 & 0 & 2 \\
\hline & & $\%$ & 0 & 0 & 0 & 4.0 & 0 & 0 & 0 & 8.0 \\
\hline \multirow[t]{8}{*}{ Control } & Caucasian & $\#$ & $59 / 4,296^{1}$ & $30 / 4,296^{2}$ & $8 / 4,298^{3}$ & $259 / 4,298^{4,10}$ & $7 / 4,297^{5}$ & $1 / 3,953^{6}$ & $6 / 3,980^{7}$ & $406 / 4,300$ \\
\hline & & $\%$ & 1.4 & 0.7 & 0.2 & 6.0 & 0.2 & 0.03 & 0.2 & 9.4 \\
\hline & African-American & \# & $7 / 2,200^{1}$ & $3 / 2,201^{2}$ & $274 / 2,201^{3,8,9}$ & $35 / 2,203^{4,11}$ & $0 / 2,203^{5}$ & $169 / 2,075^{6,12,13}$ & $56 / 2,086^{7}$ & $388 / 2,203$ \\
\hline & & $\%$ & 0.3 & 0.1 & 12.4 & 1.6 & 0 & 8.1 & 2.7 & 17.6 \\
\hline & Hispanic & \# & - & $1 / 121$ & $1 / 121^{8}$ & $14 / 121^{10,11}$ & - & $0 / 121^{12}$ & $0 / 121$ & $16 / 121$ \\
\hline & & $\%$ & - & 0.8 & 0.8 & 11.6 & - & 0 & 0 & 13.2 \\
\hline & Asian & $\#$ & - & $0 / 286$ & $0 / 286^{9}$ & $7 / 286$ & - & $0 / 286^{13}$ & $0 / 286$ & $7 / 286$ \\
\hline & & $\%$ & - & 0 & 0 & 2.4 & - & 0 & 0 & 2.4 \\
\hline
\end{tabular}

Superscript numbers highlight comparisons between specific subgroups and the respective $P$ values for these comparisons. For example, ${ }^{1}$ indicates a comparison of the frequency of the K8 G62C variant in Caucasian versus African-American controls. ${ }^{1} P<0.0001 ;{ }^{2} P<0.002 ;{ }^{3} P<0.0001 ;{ }^{4} P<0.0001 ;{ }^{5} P=0.1 ;{ }^{6} P<0.0001 ;{ }^{7} P<0.0001$;

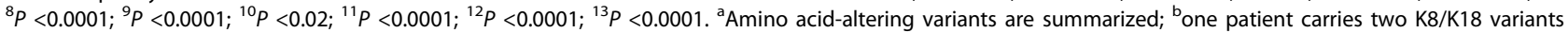
(K8 G62C+R341H); ' one patient carries two K8/K18 variants (K8 A333A+G434S). DILI, drug-induced liver injury 
To test whether the detected $\mathrm{K} 8 / \mathrm{K} 18$ variants are overrepresented among DILI subjects, we compared their frequencies in DILI patients with data from public databases. All common variants, as well as the total amino acid-altering $\mathrm{K} 8 / \mathrm{K} 18$ variants, were found at comparable frequencies in DILI subjects and ethnically matched controls (Table 3); and similar results were obtained when only patients with high causality scores (of 1, 2, 3) were analyzed (not shown). As reported previously, several variants segregated with specific ethnicities. In particular, K8 G62C, I63V, R341H and V380I were overrepresented in Caucasians as compared to AfricanAmerican controls; whereas K8 A333A, G434S and V480I were more common in African-Americans (Table 3). Although the data on Hispanic and Asian controls were rather limited, they demonstrated that K8 R341H is particularly common among Hispanics (that is, significantly more common than in both African-Americans and
Caucasians), while African-American-enriched variants (K8 A333A and G434S) are rare in this group (Table 3).

The most frequently implicated agents in our cohort included amoxicillin-clavulanate, isoniazid and nitrofurantoin-induced DILI, and all these subgroups displayed similar distribution of K8/K18 variants (see Additional file 2: Table S1). Further analysis revealed that K8/K18 variants are distributed similarly among patients with different DILI causality or severity scores as well as injury patterns (Tables 4, 5 and 6). However, there is a trend of amino acid-altering keratin variants to associate with fatal/severe DILI (14\%) as compared with moderate/mild DILI (9.7 \%; $P=0.09$; Table 4 ) and this trend became more obvious when only patients with high causality scores were analyzed (14.3\% versus $8.7 \%$; $P=0.05)$.

To better understand the biological significance of these newly identified K8/K18 variants, we studied their

Table 4 Distribution of keratin variants among DILI patients stratified by severity

\begin{tabular}{|c|c|c|c|c|c|c|}
\hline \multirow[t]{4}{*}{ Variant } & \multicolumn{6}{|l|}{ Severity } \\
\hline & Fatal (5) & Severe (4) & Mod hosp (3) & Mod (2) & Mild (1) & Total \\
\hline & \# (\%) & \# (\%) & \# (\%) & \# (\%) & \# (\%) & \# (\%) \\
\hline & $71(8.9)$ & $144(18.0)$ & 221 (27.6) & $176(22.0)$ & $188(23.5)$ & $800(100)$ \\
\hline K8 Y54H & 0 & 0 & 0 & 0 & $1(0.5)$ & $1(0.1)$ \\
\hline K8 G62C & 0 & $3(2.1)$ & $2(0.9)$ & $3(1.7)$ & $3(1.6)^{d}$ & $11(1.4)$ \\
\hline K8 I63V & $1(1.4)$ & $2(1.4)$ & $2(0.9)$ & $1(0.6)$ & $3(1.6)$ & $9(1.1)$ \\
\hline IVS1+30G>A & 0 & 0 & $1(0.5)$ & 0 & 0 & $1(0.1)$ \\
\hline K8 A333A & $2(2.8)$ & $4(2.8)$ & $5(2.3)$ & $1(0.6)^{c}$ & $3(1.6)$ & $15(1.9)$ \\
\hline K8 R341H & $5(7.0)$ & $5(3.5)$ & $13(5.9)^{b}$ & $7(4.0)$ & $10(5.3)^{d}$ & $40(5.0)$ \\
\hline K8 I346V & 0 & $1(0.7)^{\mathrm{a}}$ & 0 & 0 & 0 & $1(0.1)$ \\
\hline K8 A351V & 0 & 0 & 0 & 0 & $1(0.5)$ & $1(0.1)$ \\
\hline K8 A358V & 0 & $1(0.7)$ & 0 & 0 & 0 & $1(0.1)$ \\
\hline K8 V380I & 0 & $1(0.7)$ & 0 & $1(0.6)$ & $1(0.5)$ & $3(0.4)$ \\
\hline K8 K393R & $1(1.4)$ & 0 & 0 & 0 & 0 & $1(0.1)$ \\
\hline IVS6+46A>T & 0 & $3(2.1)^{\mathrm{a}}$ & $4(1.8)$ & $1(0.6)$ & $2(1.1)$ & $10(1.3)$ \\
\hline K8 G434S & $1(1.4)$ & $4(2.8)$ & $2(0.9)$ & $2(1.1)^{c}$ & $1(0.5)$ & $10(1.3)$ \\
\hline K8 V461V & 0 & 0 & 0 & $1(0.6)$ & 0 & $1(0.1)$ \\
\hline K8 V480I & $1(1.4)$ & $3(2.1)$ & $2(0.9)$ & $1(0.6)$ & 0 & $7(0.9)$ \\
\hline IVS8+8C>T & 0 & $1(0.7)$ & 0 & 0 & 0 & $1(0.1)$ \\
\hline IVS8+38G>A & 0 & 0 & $1(0.5)$ & 0 & 0 & $1(0.1)$ \\
\hline IVS8+27del9nt & 0 & 0 & $1(0.5)$ & 0 & 0 & $1(0.1)$ \\
\hline $\mathrm{K} 18-11 \mathrm{C}>\mathrm{T}$ & 0 & 0 & $1(0.5)^{b}$ & 0 & 0 & $1(0.1)$ \\
\hline K18 $\Delta 65-72$ & 0 & 0 & 0 & 0 & $1(0.5)$ & $1(0.1)$ \\
\hline K18 D89H & $1(1.4)$ & 0 & 0 & 0 & 0 & $1(0.1)$ \\
\hline \# (\%) patients with amino acid-altering variants & $10(14.1)$ & $20(13.9)$ & $21(9.5)$ & $15(8.5)$ & $20(10.6)$ & $86(10.8)$ \\
\hline \# (\%) patients with intronic variants & 0 & $4(2.8)$ & $8(3.6)$ & $1(0.6)$ & $2(1.1)$ & $15(1.9)$ \\
\hline
\end{tabular}

${ }^{\mathrm{a}}$ One patient carries two K8/K18 variants (K8 I346V+IVS6+46A>T); ${ }^{\mathrm{b}}$ one patient carries two K8/K18 variants (K8 R341H+K18-11C>T); ${ }^{\mathrm{C}}$ one patient carries two K8/K18 variants (K8 A333A+G434S); ${ }^{d}$ one patient carries two K8/K18 variants (K8 G62C+R341H); DILI, drug-induced liver injury; Mod, moderate non-hospitalized; Mod hosp, moderate hospitalized 
Table 5 Distribution of keratin variants among DILI patients stratified by causality scores

\begin{tabular}{|c|c|c|c|c|c|c|}
\hline \multirow[t]{4}{*}{ Variant } & \multicolumn{6}{|l|}{ Causality $^{e}$} \\
\hline & Definitive & Very likely & Probable & Possible & Unlikely & Total \\
\hline & \# (\%) & \# (\%) & \# (\%) & \# (\%) & \# (\%) & \# (\%) \\
\hline & $190(23.8)$ & $312(39.0)$ & 148 (18.5) & $110(13.8)$ & $39(4.8)$ & $800(100)$ \\
\hline K8 Y54H & 0 & 0 & 0 & $1(0.9)$ & 0 & $1(0.1)$ \\
\hline K8 G62C & $3(1.6)$ & $5(1.6)^{b}$ & $2(1.4)$ & $1(0.9)$ & 0 & $11(1.4)$ \\
\hline K8 I63V & $2(1.1)$ & $3(1.0)$ & $2(1.4)$ & 0 & $2(5.1)$ & $9(1.1)$ \\
\hline IVS1+30G >A & 0 & 0 & $1(0.7)$ & 0 & 0 & $1(0.1)$ \\
\hline K8 A333A & $3(1.6)$ & $2(0.6)$ & $3(2.3)$ & $4(3.6)^{d}$ & $3(7.7)$ & $15(1.9)$ \\
\hline K8 R341H & $8(4.2)^{a}$ & $14(4.5)^{b}$ & $8(5.4)$ & $9(8.2)$ & $1(2.6)$ & $40(5.0)$ \\
\hline K8 I346V & 0 & $1(0.3)^{c}$ & 0 & 0 & 0 & $1(0.1)$ \\
\hline K8 A351V & $1(0.5)$ & 0 & 0 & 0 & 0 & $1(0.1)$ \\
\hline K8 A358V & $1(0.5)$ & 0 & 0 & 0 & 0 & $1(0.1)$ \\
\hline K8 V380I & $1(0.5)$ & 0 & 0 & $1(0.9)$ & $1(2.6)$ & $3(0.4)$ \\
\hline K8 K393R & 0 & 0 & $1(0.7)$ & 0 & 0 & $1(0.1)$ \\
\hline IVS6+46A>T & $2(1.1)$ & $3(1.0)^{c}$ & $4(2.7)$ & $1(0.9)$ & 0 & $10(1.3)$ \\
\hline K8 G434S & $2(1.1)$ & $2(0.6)$ & $2(1.4)$ & $4(3.6)^{d}$ & 0 & $10(1.3)$ \\
\hline K8 V461V & 0 & 0 & 0 & 0 & $1(2.6)$ & $1(0.1)$ \\
\hline K8 V480I & 0 & $5(1.6)$ & $2(1.4)$ & 0 & 0 & $7(0.9)$ \\
\hline IVS8+8C $>T$ & $1(0.5)$ & 0 & 0 & 0 & 0 & $1(0.1)$ \\
\hline IVS8+38G>A & 0 & 0 & 0 & $1(0.9)$ & 0 & $1(0.1)$ \\
\hline IVS8+27del9nt & 0 & 0 & 0 & $1(0.9)$ & 0 & $1(0.1)$ \\
\hline $\mathrm{K} 18-11 \mathrm{C}>\mathrm{T}$ & $1(0.5)^{\mathrm{a}}$ & 0 & 0 & 0 & 0 & $1(0.1)$ \\
\hline K18 $\Delta 65-72$ & 0 & $1(0.3)$ & 0 & 0 & 0 & $1(0.1)$ \\
\hline $\mathrm{K} 18 \mathrm{D} 89 \mathrm{H}$ & 0 & $1(0.3)$ & 0 & 0 & 0 & $1(0.1)$ \\
\hline \# (\%) patients with amino acid-altering variants & $18(9.5)$ & $31(9.9)$ & $17(11.5)$ & $16(14.6)$ & $4(10.3)$ & $86(10.8)$ \\
\hline \# (\%) patients with intronic variants & $4(2.1)$ & $3(1.0)$ & $5(3.4)$ & $3(2.7)$ & 0 & $15(1.9)$ \\
\hline
\end{tabular}

${ }^{\mathrm{a}}$ One patient carries two K8/K18 variants (K8 R341H+K18-11C>T); ${ }^{\mathrm{b}}$ one patient carries two K8/K18 variants (K8 G62C+R341H); ${ }^{\mathrm{C}}$ one patient carries two K8/K18 variants (K8 I346V+IVS6+46A>T); ${ }^{d}$ one patient carries two K8/K18 variants (K8 A333A+G434S); ${ }^{e}$ the causality score was not known in one patient. DILI, drug-induced liver injury

conservation by multiple sequence comparison. K8 K393R and K18 D89H variants were conserved both among species and type I and II keratins, respectively, which meshes well with the fact that they are located in the particularly conserved amino-terminal (K18 D89H, in an Asian patient with isoniazid-induced DILI) or carboxy-terminal regions (K8 K393R, in a Caucasian patient with ezetimibe and simvastatin-induced DILI) of the rod domain (Fig. 2) [2, 8]. Consistent with their biologically predicted importance due to amino acid conservation, both variants were found in patients with fatal DILI that otherwise constitutes $<10 \%$ of our cohort (Table 4 ). Both variants were observed in cholestatic DILI and were not detected among $>300$ Asian and $>5,000$ Caucasian controls analyzed so far, or available in the above described public databases (not shown). The $\mathrm{K} 8 \mathrm{~A} 358 \mathrm{~V}$ variant was conserved among $\mathrm{K} 8$ from different species but not among other type II keratins and was detected in one subject with severe DILI (Table 4; Additional file 3: Figure S2). On the other hand, the non-conserved K8 A351V variant was observed in a participant with mild DILI.

\section{In vitro transfection experiments}

To address the impact of the novel K8/K18 variants on keratin filament network architecture, we performed transient transfections in NIH 3T3 cells (Fig. 3). Importantly, both K8 K393R and K18 D89H, but not the other $\mathrm{K} 8 / \mathrm{K} 18$ variants, resulted in significantly more frequent disruption of the keratin filament network (Fig. 3). Collectively, these data suggest that rare $\mathrm{K} 8 / \mathrm{K} 18$ variants which result in disruption of the keratin cytoskeleton are likely to predispose to severe DILI.

\section{Discussion}

Our results demonstrate that keratin variants are not overrepresented in DILI patients, which contrasts with 
Table 6 Distribution of keratin variants among DILI patients stratified by laboratory injury profile

\begin{tabular}{|c|c|c|c|c|}
\hline \multirow[t]{4}{*}{ Variant } & \multicolumn{4}{|l|}{ Injury type } \\
\hline & Hepatocellular & Cholestatic & Mixed & Total \\
\hline & \# (\%) & \# (\%) & \# (\%) & \# (\%) \\
\hline & $438(54.8)$ & $198(24.7)$ & $164(20.5)$ & $800(100)$ \\
\hline K8 Y54H & 0 & $1(0.5)$ & 0 & $1(0.1)$ \\
\hline K8 G62C & $5(1.1)$ & $4(2.0)^{c}$ & $2(1.2)$ & $11(1.4)$ \\
\hline K8 I63V & $8(1.8)$ & $1(0.5)$ & 0 & $9(1.1)$ \\
\hline IVS1+30G >A & 0 & 0 & $1(0.6)$ & $1(0.1)$ \\
\hline K8 A333A & $4(0.9)$ & $7(3.5)^{d}$ & $4(2.4)$ & $15(1.9)$ \\
\hline K8 R341H & $21(4.8)^{a}$ & $10(5.0)^{c}$ & $9(5.5)$ & $40(5.0)$ \\
\hline K8 I346V & $1(0.2)^{b}$ & 0 & 0 & $1(0.1)$ \\
\hline K8 A351V & $1(0.2)$ & 0 & 0 & $1(0.1)$ \\
\hline K8 A358V & 0 & $1(0.5)$ & 0 & $1(0.1)$ \\
\hline K8 V380I & 0 & $1(0.5)$ & $2(1.2)$ & $3(0.4)$ \\
\hline K8 K393R & 0 & $1(0.5)$ & 0 & $1(0.1)$ \\
\hline IVS6+46A>T & $7(1.6)^{b}$ & $1(0.5)$ & $2(1.2)$ & $10(1.3)$ \\
\hline K8 G434S & $5(1.1)$ & $5(2.5)^{d}$ & 0 & $10(1.3)$ \\
\hline K8 V461V & $1(0.2)$ & 0 & 0 & $1(0.1)$ \\
\hline K8 V480I & $5(1.1)$ & $2(1.0)$ & 0 & $7(0.9)$ \\
\hline IVS8+8C $>\mathrm{T}$ & $1(0.2)$ & 0 & 0 & $1(0.1)$ \\
\hline IVS8+38G >A & 0 & 0 & $1(0.6)$ & $1(0.1)$ \\
\hline IVS8+27del9nt & $1(0.2)$ & 0 & 0 & $1(0.1)$ \\
\hline $\mathrm{K} 18-11 \mathrm{C}>\mathrm{T}$ & $1(0.2)^{\mathrm{a}}$ & 0 & 0 & $1(0.1)$ \\
\hline K18 $\Delta 65-72$ & $1(0.2)$ & 0 & 0 & $1(0.1)$ \\
\hline K18 D89H & 0 & $1(0.5)$ & 0 & $1(0.1)$ \\
\hline $\begin{array}{l}\text { \# (\%) patients with } \\
\text { amino acid-altering } \\
\text { variants }\end{array}$ & $46(10.5)$ & 27 (13.6) & $13(7.9)$ & $86(10.8)$ \\
\hline $\begin{array}{l}\text { \# (\%) patients with } \\
\text { intronic variants }\end{array}$ & $10(2.3)$ & $1(0.5)$ & $4(2.4)$ & $15(1.9)$ \\
\hline
\end{tabular}

${ }^{\mathrm{a}}$ One patient carries two $\mathrm{K} 8 / \mathrm{K} 18$ variants (K8 R341H+K18-11C $\left.>\mathrm{T}\right) ;{ }^{\mathrm{b}}$ one patient carries two $\mathrm{K} 8 / \mathrm{K} 18$ variants ( $\mathrm{K} 8 \mathrm{I} 346 \mathrm{~V}+\mathrm{IVS} 6+46 \mathrm{~A}>\mathrm{T}$ ); ${ }^{\mathrm{C}}$ one patient carries two $\mathrm{K} 8 / \mathrm{K} 18$ variants $(\mathrm{K} 8 \mathrm{G} 62 \mathrm{C}+\mathrm{R} 341 \mathrm{H})$; ${ }^{d}$ one patient carries two $\mathrm{K} 8 / \mathrm{K} 18$ variants (K8 A333A+G434S); DILI, drug-induced liver injury

the data from patients with chronic hepatitis $\mathrm{C}$, primary biliary cirrhosis and ALF $[8,19]$. This lack of overall association of K8/K18 variants with DILI may, in part, be due to the limited number of cases attributed to an individual agent, since this cohort of 800 cases included over 250 individual drugs and herbal and dietary supplements. Along these lines, previous reports suggested that K8/K18 variants predispose only to specific forms of liver injury. For example, exonic variants were not found to predispose to disease development in patients with hemochromatosis [17], and transgenic animals carrying the K18 R90C variant were markedly susceptible to Fas- but not TNF $\alpha$-induced apoptosis as well as to thioacetamide- but not carbon tetrachloride-induced liver fibrosis [32].
To evaluate the importance of $\mathrm{K} 8 / \mathrm{K} 18$ variants in DILI, we took advantage of large, publicly available databases that allowed us to compare our results with a larger control population than the previous studies $[8,19]$. Multiple K8/K18 variants were confirmed and shown to associate with specific ethnic backgrounds $[19,30]$ and $\mathrm{R} 341 \mathrm{H}$ has been demonstrated to constitute the most common amino acid-altering $\mathrm{K} 8 / \mathrm{K} 18$ variant in Asians (Table 3). In addition, K8 A333A, G434S and V480I were largely restricted to African-Americans as compared to both Asians and Hispanics. While the exact reason for the enrichment of certain $\mathrm{K} 8 / \mathrm{K} 18$ variants in specific ethnic backgrounds remains unknown, unequal ethnic distribution of human variants is relatively common and is caused by adaption to local factors [33, 34].

The data from publicly available databases indicate that the frequency of several common variants is higher than previous estimations. In particular, $\mathrm{K} 8 \mathrm{G} 62 \mathrm{C}$ and $\mathrm{R} 341 \mathrm{H}$ variants were detected in $1.4 \%$ and $6 \%$ of US Caucasian controls, respectively (versus $0.9 \%$ and $3.2 \%$ as reported previously [19, 35]). These data should therefore inform future studies that examine K8/K18 variants in different disease contexts.

While we found no overrepresentation of common K8/K18 variants in DILI subjects, we observed a clear trend towards clustering of these variants in the more severe cases. However, due to the relatively low numbers, further studies are needed to confirm this observation that is reminiscent of the situation with ALF, where the presence of $\mathrm{K} 8 / \mathrm{K} 18$ variants was associated with adverse outcomes [19]. Moreover, we detected several previously unknown variants that are likely to have biological importance. As such, K8 K393R and K18 D89H are the first described simple epithelial keratin variants located in the most conserved helix initiation/termination motifs (HIM/HTM) of the rod domain (Fig. 2e). Of note, mutations in these domains have been presumed to be embryolethal in humans $[19,35,36]$ and represent the most important and abundant disease-causing mutational hotspots in epidermal keratins and other IFs (Fig. 2e) $[2,8,13,37]$. The observed keratin network disruption in cells transfected with K8 K393R or K18 D89H further strengthens their biological significance. Although the performed transfection experiments cannot fully evaluate the importance of both variants in vivo, the conserved K18 D89H represents a non-conservative substitution since it alters protein charge. Moreover, it is only one residue away from K18 R90C (Fig. 2) whose overexpression in transgenic mice causes a marked susceptibility to a variety of drug-induced liver injuries [8, 35]. While K8 K393R might be considered a conservative substitution, the same mutation in a less conserved region of K5 (that is, K5 K199R) was sufficient to cause EBS [38]. Hence, structural considerations, cell culture experiments, transgenic mouse data 


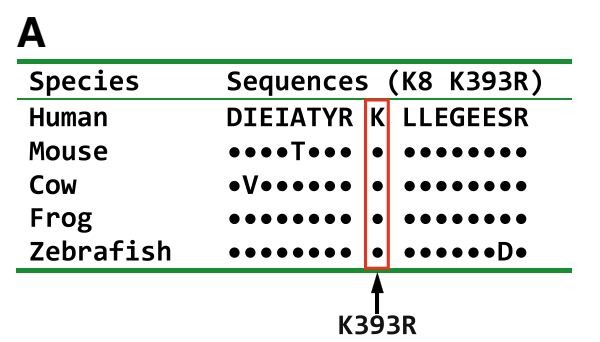

C

\begin{tabular}{|c|c|}
\hline Species & Sequences (K18 D89H) \\
\hline Human & KETMQSLN D RLASYLDR \\
\hline Mouse & $\bullet \bullet \bullet D \bullet \bullet|\bullet| \bullet \bullet \bullet \bullet K$ \\
\hline Cow & $\bullet \bullet \bullet \bullet D \bullet \bullet-\bullet \bullet \bullet \bullet \bullet E K$ \\
\hline $\begin{array}{l}\text { Frog } \\
\text { Zebrafish }\end{array}$ & \begin{tabular}{l|ll}
$\bullet M A \bullet \bullet N \bullet \bullet$ & $\bullet \bullet \bullet \bullet \bullet K K$ \\
$O \bullet V \bullet \bullet G \bullet \bullet$ & $\bullet \bullet G \bullet \bullet K R$
\end{tabular} \\
\hline
\end{tabular}

E

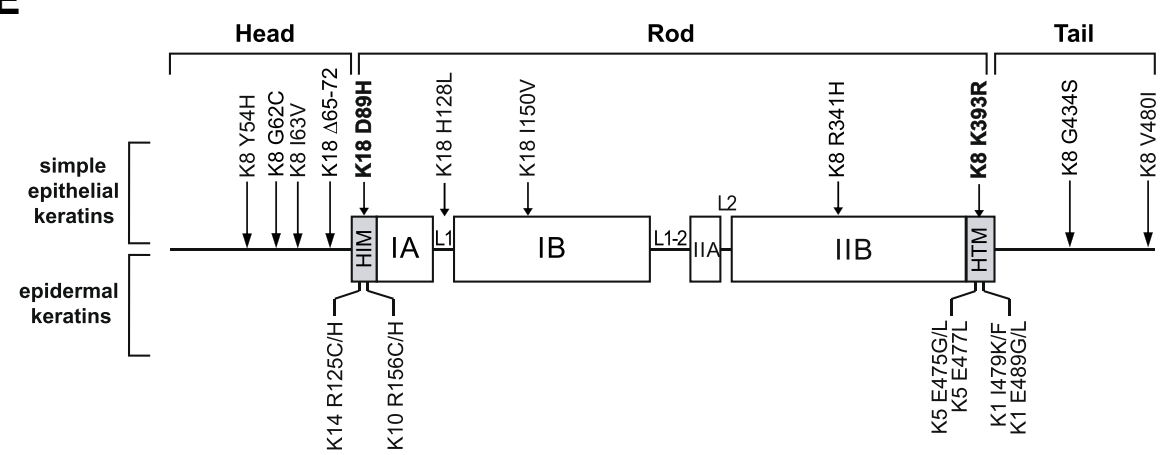

B

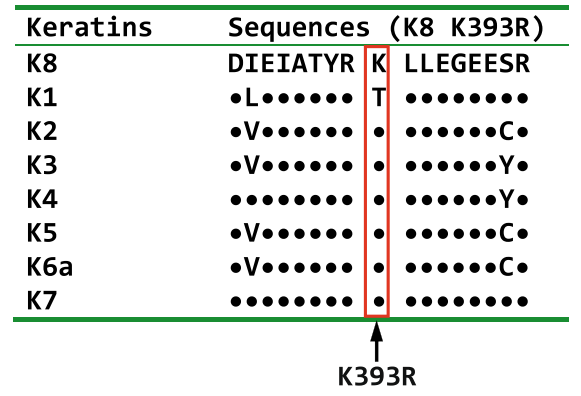

D

\begin{tabular}{|c|c|c|}
\hline Keratins & Sequences & 5 (K18 D89H) \\
\hline K18 & KETMQSLN & D RLASYLDR \\
\hline K9 & $\bullet S \bullet \bullet \bullet E \bullet \bullet$ & S $\bullet \bullet \bullet \bullet K$ \\
\hline K10 & $\bullet \mathrm{V} \bullet \bullet \bullet N \bullet \bullet$ & $\bullet \bullet \bullet \bullet \bullet \bullet \bullet K$ \\
\hline K12 & $\bullet \bullet \bullet \bullet \bullet N \bullet \bullet$ & $\bullet \bullet \bullet \bullet \bullet \bullet \bullet K$ \\
\hline K13 & $\bullet \mathrm{I} \bullet \bullet \bullet N \bullet \bullet$ & $\bullet \bullet \bullet \bullet \bullet \bullet$ EK \\
\hline K14 & $\bullet \mathrm{V} \bullet \bullet \bullet N \bullet \bullet$ & $\bullet \bullet \bullet \bullet \bullet \bullet \bullet K$ \\
\hline K15 & $\bullet \mathrm{I} \bullet \bullet \bullet N \bullet \bullet$ & $\bullet \bullet \bullet \bullet \bullet \bullet \bullet K$ \\
\hline K16 & $\bullet \mathrm{V} \bullet \bullet \bullet N \bullet \bullet$ & $\bullet \bullet \bullet \bullet \bullet \bullet \bullet K$ \\
\hline K17 & $\bullet \mathrm{A} \bullet \bullet \bullet N \bullet \bullet$ & $\bullet \bullet \bullet \bullet \bullet \bullet \bullet K$ \\
\hline K19 & $\bullet \mathrm{L} \bullet \bullet \bullet N \bullet \bullet$ & $\bullet \bullet \bullet \bullet \bullet \bullet \bullet K$ \\
\hline K20 & $\bullet \mathrm{MA} \bullet \bullet N \bullet \bullet$ & $\bullet \bullet \bullet \bullet \bullet \bullet E K$ \\
\hline
\end{tabular}

Fig. 2 K8 K393R and K18 D89H are the first identified simple epithelial keratin variants located in the most conserved regions of the rod domain. Conservation of the novel K8 K393R/K18 D89H variants among $(\mathbf{a}, \mathbf{c})$ species and $\mathbf{b}$ type II or $\mathbf{d}$ type I keratins (standard single-letter amino acid abbreviations are used). Sequences surrounding the novel K8/K18 variants are depicted. Dots highlight conserved amino acids. e Distribution of simple epithelial and epidermal keratin variants within the keratin backbone. The schematic shows the characteristic tripartite structure ( $\mathrm{N}$-terminal 'head', central 'rod' and C-terminal 'tail' domains) of all IFs including keratins. The rod domain is subdivided into IA, IB, IIA, and IIB subdomains that in turn are separated through linker (L1, L1-2, L2) sequences. The shaded regions are the most conserved segments of the rod domain (termed helix initiation motif ' $H I M$ ' and helix termination motif ' $H T M$ ') and constitute mutation 'hot spots' in severe epidermal keratins and other IF mutations. Note that unlike epidermal keratins, the frequent human K8/K18 variants are located outside HIM/HTM. IF, intermediate filament

and the fact that both patients with K8 K393R/K18 D89H variants suffered fatal DILI collectively make a strong case for the importance of these substitutions in DILI outcomes.

Although the exact pathogenesis of DILI remains to be clearly defined [22], K8/K18 deficiency results in multiple cellular dysfunctions that likely contribute to development/progression of this type of liver injury. For example, keratins constitute important mechanoprotective 

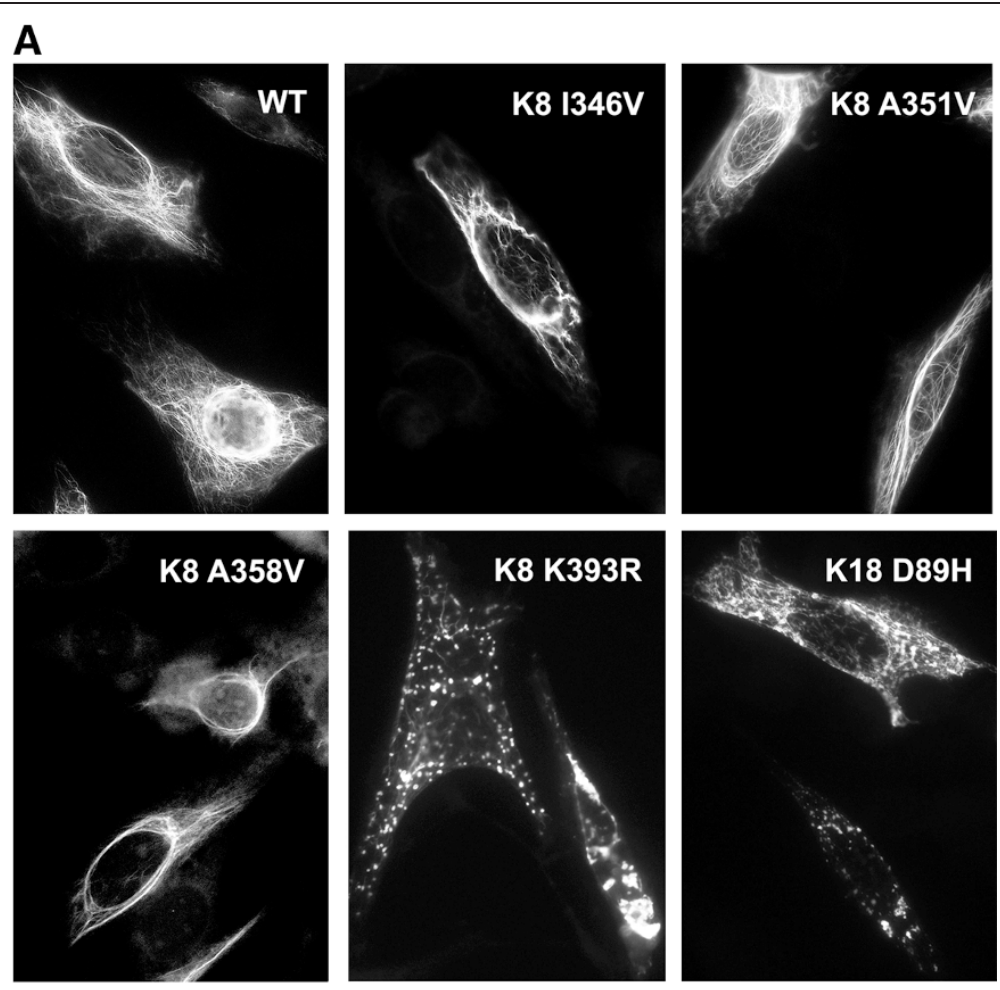

B

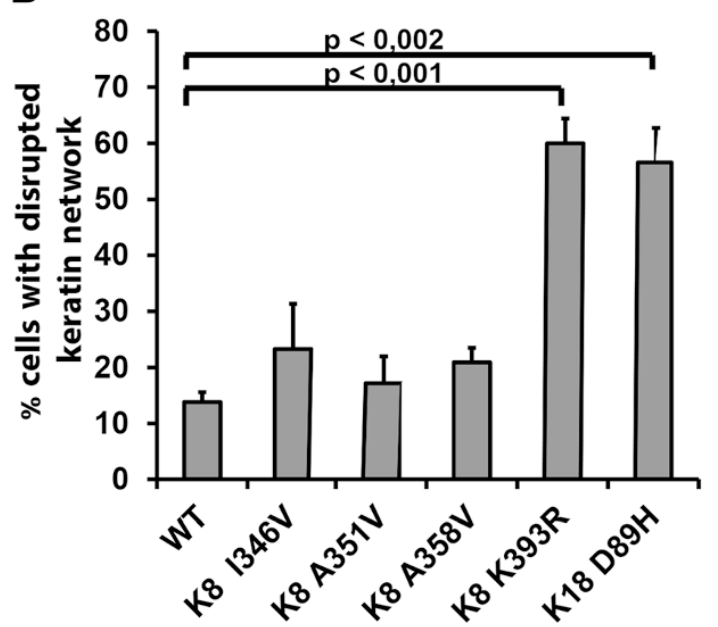

Fig. $3 \mathrm{~K} 8 \mathrm{~K} 393 \mathrm{R}$ and K18 D89H variants result in keratin network disruption. a NIH 3T3 cells were transiently transfected with wild-type K8/K18 (WT) or a combination of K8/K18 variants and a WT partner keratin and stained with an anti-K18 antibody. Transfections were performed in triplicate. $\mathbf{b}$ The percentage of cells with disrupted keratin filaments was quantified. At least 100 cells were counted in each experiment

susceptibility to oxidative stress [40, 41]. Furthermore, keratins act as signalling platforms and are important for protein localization/targeting, modulation of protein synthesis, cell growth or proliferation [3, 8, 42-44]. Although the commonly found $\mathrm{K} 8$ variants do not result in obvious keratin network redistribution under basal condition, they do so under various stress situations such as oxidative stress or upon hyperphosphorylation conditions [45]. In that respect, $\mathrm{K} 8 \mathrm{G} 62 \mathrm{C} / \mathrm{R} 341 \mathrm{H} / \mathrm{R} 341 \mathrm{C}$ variants predisposed transgenic mice to acetaminophen-induced liver injury and this predisposition was associated with a more prominent keratin network disruption after the exposure to the drug [46].

Fortunately severe clinical outcomes with DILI are uncommon, with less than $10 \%$ of patients requiring a liver transplant or dying within 6 months of DILI onset [47]. However, additional genetic studies that focus on the HIM/HTM domains of simple epithelial keratins are 
likely to provide important information regarding the prevalence of fatal DILI in individuals with HIM/HTM keratin variants. We also anticipate that specific drugs, and potentially specific race and ethnic background variants, are likely to play important roles in this process.

\section{Conclusions}

Our study has uncovered variants in highly conserved residues of K8 Lys393Arg and K18 Asp89His in patients with fatal DILI. These first to be described novel variants represent for the first time described 'epidermal-like' K8/K18 variants which lead to keratin network disruption in untreated cells. Common K8/K18 variants were found at similar frequencies in DILI subjects and ethnically matched population controls. Thus, rare $\mathrm{K} 8 / \mathrm{K} 18$ variants may predispose to DILI development in a subset of patients.

\section{Additional files}

Additional file 1: Figure S1. Identification of the novel variants (A) K8 K393R and (B) K18 D89H. A comparison with wild type (WT) sequences (left panels) reveals the heterozygous nature of the depicted variants. Standard single-letter amino acid abbreviations are used. (PDF $2587 \mathrm{~kb}$ )

Additional file 2: Table S1. Distribution of K8 and K18 variants in selected drug categories. (DOCX $44 \mathrm{~kb}$ )

Additional file 3: Figure S2. Conservation of the novel K8 variants among $(\mathbf{A}, \mathbf{C}, \mathbf{E})$ species and among $(\mathbf{B}, \mathbf{D}, \mathbf{F})$ type $\|$ keratins. Sequences surrounding the novel $\mathrm{K} 8$ variants are depicted. Dots highlight conserved amino acids (listed using standard single-letter abbreviations). (PDF 530 kb)

\section{Abbreviations}

AA: African-American; ALF: Acute liver failure; DILI: Drug-induced liver injury; DILIN: DILI Network; DMEM: Dulbecco's modified Eagle's medium; EBS: Epidermolysis bullosa simplex; EDTA: Ethylenediaminetetraacetic acid; FCS: Fetal calf serum; HIM: Helix initiation motif; HPLC: High-performance liquid chromatography; HTM: Helix termination motif; IF: Intermediate filament; K: Keratin; K8: Keratin 8; K18: Keratin 18; PBS: Phosphate-buffered saline; PCR: Polymerase chain reaction.

\section{Competing interests}

The authors declare that they have no competing interests.

\section{Authors' contributions}

VU performed data acquisition, analysis and interpretation, statistical analysis, and drafted and critically revised the manuscript. TJU and RJF performed data analysis and interpretation, technical or material support, and critically revised the manuscript. AG helped with data acquisition, analysis and interpretation, statistical analysis, and critically revised the manuscript. SI performed data acquisition. MBO produced the study concept and design, provided study supervision, performed data analysis and interpretation, and critically revised the manuscript. PS produced the study concept and design, obtained funding, provided study supervision, performed data analysis and interpretation, and drafted and critically revised the manuscript. All authors read and approved the final version of the manuscript.

\section{Acknowledgments}

We thank Kristina Diepold and Elke Preiß for their expert technical assistance, and Ozlem Kucukoglu for her overall experimental assistance. Participation of following DILIN clinical sites is gratefully acknowledged: University of Indiana: Naga Chalasani, MD, Pl; Marwan S Ghabril, MD, Sub-l; Suthat Liangpunsakul, MD, Sub-l; Raj Vuppalanchi, MD, Sub-l; (Audrey Corne, RN, CCRN, DCF Contact, Study Coord; Sherrie Cummings, RN, BSN, Study Coord); University of California, San Francisco: Tim Davern II, MD, PI; Maurizio Bonacini, MD, Sub-l; (Benjamin Luna, Study Coord; Juliana Ma, Co-Coord); University of
Michigan: Robert J Fontana, MD, Pl; Hari Conjeevaram, MD, Sub-l; Richard Moseley, MD, Sub-l; (Kristin Chesney, MBA, Co-Coord; Angela Liu, MPH, Co-Coord); University of North Carolina at Chapel Hill: Paul Watkins, MD, Pl; Kimberly Beavers, MD, Sub-l; Herbert Bonkovsky, MD, Sub-l; Jama Darling, MD, Sub-l; Paul H Hayashi, MD, Sub-l; James Lewis, MD, Sub-l; Steven Lichtman, MD, Sub-l; Mark Russo, MD, Sub-l; Roshan Shrestha, MD, Sub-l; Steven Zacks, MD, Sub-l; (Tracy Russell, CCRP, DCF Contact, Study Coord).

\section{Satellite sites}

Carolinas Medical Center and Charlotte Campus of UNC School of Medicine: Herbert L Bonkovsky, MD, PI; Gregory Conner, MD, Sub-l; Vani Gopalreddy, MD, Sub-l; Mark Russo, MD, Sub-l; (Amanda Balasco, MLT (ASCP), Study Coord; Gale Groseclose, RN, BSN, Study Coord; Regina McFadden, RN, Co-Coord); University of Texas Southwestern: William Lee, MD, Pl; Lafaine Grant, MD, Sub-l; Mamta Jain, MD, Sub-l; Dwaine Thiele, MD, Sub-l; (Theresa Hardwick, RN, CCRC, Study Coord; Stacey Minshall, BSN RN, Study Coord); University of Southern California: Andrew Stolz, MD, Pl; Neil Kaplowitz, MD, Sub-l; (Susan Milstein, RN, BSN, Study Coord). University of California, Los Angeles: Francisco A Durazo, MD, Pl; (Yolanda C Melgoza, Study Coord; Val Peacock, RN BSN, Co-Coord); Mayo Clinic: Jayant A Talwalkar, MD, MPH, Pl; (Bonnie Donelan-Dunlap, Co-Coord; Donna Stejskal, Co-Coord); Albert Einstein: Victor J Navarro, MD, Pl; Manisha Verma, MD, Sub-l; (Maricruz Vega, MPH, CHES, DCF Contact).

University of Pennsylvania: K Rajender Reddy, MD, Pl; (Amina A Wirjosemito, MPH, Study Coord; Emily T Panik, MPH, Co-Coord); Mount Sinai: Joseph Odin, MD, Pl; Jawad Ahmad, MD, Sub-l; Meena Bansai, MD, Sub-l; Charissa Chang, MD, Sub-l; Douglas Dieterich, MD, Sub-l; Priya Grewal, MD, Sub-l; Lawrence Liu, MD, Sub-l; Thomas Schiano, MD, Sub-l; (Varun Kesar, Study Coord); DILIN Data Coordinating Center at Duke Clinical Research Institute: Huiman X Barnhart, PhD, Pl; Hans Tillman, MD, Sub-l; David Goldstein, PhD, Sub-l; Thomas Urban, PhD, (Duke CHGV Laboratory); Katherine Galan, RN, Project Lead; Mary Moggio, Lead CRA; Nidia Rosado, CRA; Kenari Marks, CTA; Michelle Crowder, Data Management; Carmel Scharenbroich, Data Management; Hoss Rostami, Data Management; Thomas Phillips, Programmer-Statistics; Jiezhun (Sherry) Gu, PhD, Statistician; Barbara Kuzil, Safety; National Institute of Diabetes and Digestive and Kidney Diseases (NIDDK): José Serrano, MD, Project Scientist; Rebecca J Torrance, RN, MS, Clinical Trials Specialist; Rebekah Van Raaphorst, MPH, LT, USPHS, Health Research Administrator; Francisco O Calvo, PhD, COC Contact; Jay Everhart, MD, Scientific Advisor; Jay Hoofnagle, MD, Scientific Advisor; Averell H Sherker, MD, FRCP(C), Scientific Advisor for Viral Hepatitis and Liver Diseases.

Financial support: supported by NIH grant DK52951, the Department of Veterans Affairs (both to MBO); the German Research Foundation grants STR 1095/2-1, STR 1095/4-1, SFB TRR57 and funding of the Interdisciplinary Center for Clinical Research (IZKF) in Aachen (to PS). The DILIN is structured as an U01 cooperative agreement supported by the National Institute of Diabetes and Digestive and Kidney Diseases (NIDDK) and the National Institutes of Health (NIH) with funds provided by the following grants: U01DK065193 (University of Connecticut); U01DK065211 (University of Indiana, Purdue); U01DK065238 (University of California, San Francisco/CPMC); U01DK065184 (University of Michigan, Ann Arbor); U01DK065201 (University of North Carolina at Chapel Hill, Asheville, Carolinas Medical Center, Duke); U01DK83023 (University of Texas Southwestern); U01DK083020 (University of Southern California, UCLA Pfleger Liver Institute); U01DK08992 (Mayo Clinic); U01DK083027 (University of Pennsylvania); 1U01DK100928-01 (Mount Sinai, New York); 2U01DK083027-07 (Albert Einstein Medical Center, Philadelphia); and U01DK065176 (Duke Clinical Research Institute as Data Coordinating Center).

\section{Author details}

${ }^{1}$ Department of Internal Medicine III and IZKF, University Hospital Aachen, RWTH Aachen, Pauwelsstrasse 30, D-52074 Aachen, Germany. 'Division of Pharmacotherapy and Experimental Therapeutics, Center for Pharmacogenomics and Individualized Therapy, UNC Eshelman School of Pharmacy, UNC Hamner Institute for Drug Safety Sciences, University of North Carolina, Chapel Hill, NC, USA. ${ }^{3}$ Department of Internal Medicine, University of Michigan Health System, Ann Arbor, MI, USA. ${ }^{4}$ Department of Molecular and Integrative Physiology, University of Michigan Medical School, Ann Arbor, MI, USA. ${ }^{5}$ Department of Internal Medicine I, University Medical Center UIm, Ulm, Germany.

Received: 24 December 2014 Accepted: 3 July 2015

Published online: 19 August 2015 


\section{References}

1. Coulombe PA, Omary MB. 'Hard' and 'soft' principles defining the structure, function and regulation of keratin intermediate filaments. Curr Opin Cell Biol. 2002:14:110-22.

2. Haines RL, Lane EB. Keratins and disease at a glance. J Cell Sci. 2012;125:3923-8.

3. Pan X, Hobbs RP, Coulombe PA. The expanding significance of keratin intermediate filaments in normal and diseased epithelia. Curr Opin Cell Biol. 2013:25:47-56

4. Fuchs E, Weber K. Intermediate filaments: structure, dynamics, function, and disease. Annu Rev Biochem. 1994:63:345-82.

5. Herrmann H, Strelkov SV, Burkhard P, Aebi U. Intermediate filaments: primary determinants of cell architecture and plasticity. J Clin Invest. 2009;119:1772-83.

6. Moll R, Franke WW, Schiller DL, Geiger B, Krepler R. The catalog of human cytokeratins: patterns of expression in normal epithelia, tumors and cultured cells. Cell. 1982;31:11-24.

7. Schweizer J, Bowden PE, Coulombe PA, Langbein L, Lane EB, Magin TM, et al. New consensus nomenclature for mammalian keratins. J Cell Biol. 2006:174:169-74

8. Omary MB, Ku N-O, Strnad P, Hanada S. Toward unraveling the complexity of simple epithelial keratins in human disease. J Clin Invest. 2009;119:1794-805

9. Strnad P, Paschke S, Jang KH, Ku NO. Keratins: markers and modulators of liver disease. Curr Opin Gastroen. 2012;28:209-16.

10. Omary MB, Ku N-O, Toivola DM. Keratins: guardians of the liver. Hepatology (Baltimore, MD). 2002;35:251-7.

11. Toivola DM, Strnad P, Habtezion A, Omary MB. Intermediate filaments take the heat as stress proteins. Trends Cell Biol. 2010;20:79-91.

12. Omary MB, Coulombe PA, McLean WHI. Mechanisms of disease: intermediate filament proteins and their associated diseases. New Engl J Med. 2004;351:2087-100.

13. Szeverenyi I, Cassidy AJ, Chung CW, Lee BT, Common JE, Ogg SC, et al. The Human Intermediate Filament Database: comprehensive information on a gene family involved in many human diseases. Hum Mutat. 2008;29:351-60

14. Coulombe PA, Kerns ML, Fuchs E. Epidermolysis bullosa simplex: a paradigm for disorders of tissue fragility. J Clin Invest. 2009;119:1784-93.

15. Ku NO, Michie SA, Soetikno RM, Resurreccion EZ, Broome RL, Oshima RG, et al. Susceptibility to hepatotoxicity in transgenic mice that express a dominant-negative human keratin 18 mutant. J Clin Invest. 1996;98:1034-46.

16. Loranger A, Duclos S, Grenier A, Price J, Wilson-Heiner M, Baribault H, et al. Simple epithelium keratins are required for maintenance of hepatocyte integrity. Am J Pathol. 1997;151:1673-83.

17. Strnad P, Kucukoglu O, Lunova M, Guldiken N, Lienau TC, Stickel F, et al. Non-coding keratin variants associate with liver fibrosis progression in patients with hemochromatosis. Plos One. 2012;7:e32669.

18. Zhong B, Strnad P, Selmi C, Invernizzi P, Tao G-Z, Caleffi A, et al. Keratin variants are overrepresented in primary biliary cirrhosis and associate with disease severity. Hepatology (Baltimore, MD). 2009;50:546-54.

19. Strnad P, Zhou Q, Hanada S, Lazzeroni LC, Zhong BH, So P, et al. Keratin variants predispose to acute liver failure and adverse outcome: race and ethnic associations. Gastroenterology. 2010;139:828-35.

20. Porter RM, Lane EB. Phenotypes, genotypes and their contribution to understanding keratin function. Trends Genet. 2003;19:278-85.

21. Reuben A, Koch DG, Lee WM. Acute Liver Failure Study Group. Druginduced acute liver failure: results of a U.S. multicenter, prospective study. Hepatology. 2010;52:2065-76

22. Fontana RJ. Pathogenesis of idiosyncratic drug-induced liver injury and clinical perspectives. Gastroenterology. 2014;146:914-28.

23. Watkins PB, Seligman PJ, Pears JS, Avigan MI, Senior JR. Using controlled clinical trials to learn more about acute drug-induced liver injury. Hepatology. 2008;48:1680-9.

24. Daly AK, Day CP. Genetic association studies in drug-induced liver injury. Drug Metab Rev. 2012:44:116-26.

25. Fontana RJ, Watkins PB, Bonkovsky HL, Chalasani N, Davern T, Serrano J, et al. Drug-Induced Liver Injury Network (DILIN) prospective study rationale: design and conduct. Drug Saf. 2009;32:55-68.

26. Danan G, Benichou C. Causality assessment of adverse reactions to drugs - 1. A novel method based on the conclusions of international consensus meetings: application to drug-induced liver injuries. J Clin Epidemiol. 1993;46:1323-30
27. NHLBI GO Exome Sequencing Project (ESP). Exome Variant Server. http://evs.gs.washington.edu/EVS/.

28. 1000 Genomes. http://browser.1000genomes.org/index.html.

29. Strnad P, Lienau TC, Tao GZ, Lazzeroni LC, Stickel F, Schuppan D, et al. Keratin variants associate with progression of fibrosis during chronic hepatitis C infection. Hepatology. 2006:43:1354-63.

30. Ku NO, Lim JK, Krams SM, Esquivel CO, Keeffe EB, Wright TL, et al. Keratins as susceptibility genes for end-stage liver disease. Gastroenterology. 2005;129:885-93.

31. Ku NO, Toivola DM, Zhou Q, Tao GZ, Zhong BH, Omary MB. Studying cells and simple epithelial keratins in tissues. Method Cell Biol. 2004;78:489-517.

32. Strnad P, Tao G-Z, Zhou Q, Harada M, Toivola DM, Brunt EM, et al. Keratin mutation predisposes to mouse liver fibrosis and unmasks differential effects of the carbon tetrachloride and thioacetamide models. Gastroenterology. 2008:134:1169-79.

33. Rutter M, Tienda M. The multiple facets of ethnicity. In: Ethnicity and causal mechanisms. Cambridge: Cambridge University Press; 2005. p. 50-79.

34. Genomes Project C, Abecasis GR, Auton A, Brooks LD, DePristo MA, Durbin RM, et al. An integrated map of genetic variation from 1,092 human genomes. Nature. 2012;491:56-65.

35. Ku NO, Strnad P, Zhong BH, Tao GZ, Omary MB. Keratins let liver live: mutations predispose to liver disease and crosslinking generates mallory-denk bodies. Hepatology. 2007;46:1639-49.

36. Lu H, Hesse M, Peters B, Magin TM. Type II keratins precede type I keratins during early embryonic development. Eur J Cell Biol. 2005;84:709-18.

37. Omary MB. "IF-pathies": a broad spectrum of intermediate filamentassociated diseases. J Clin Invest. 2009;119:1756-62.

38. Abu Sa'd J, Indelman M, Pfendner E, Falik-Zaccai TC, Mizrachi-Koren M Shalev S, et al. Molecular epidemiology of hereditary epidermolysis bullosa in a Middle Eastern population. J Invest Dermatol. 2006;126:777-81.

39. Weerasinghe SW, Ku N-O, Altshuler PJ, Kwan R, Omary MB. Mutation of caspase-digestion sites in keratin 18 interferes with filament reorganization, and predisposes to hepatocyte necrosis and loss of membrane integrity. J Cell Sci. 2014;127:1464-75

40. Zhou Q, Ji XH, Chen LX, Greenberg HB, Lu SC, Omary MB. Keratin mutation primes mouse liver to oxidative injury. Hepatology. 2005;41:517-25.

41. Tao GZ, Looi KS, Toivola DM, Strnad P, Zhou Q, Liao J, et al. Keratins modulate the shape and function of hepatocyte mitochondria: a mechanism for protection from apoptosis. J Cell Sci. 2009;122:3851-5.

42. Kim S, Wong P, Coulombe PA. A keratin cytoskeletal protein regulates protein synthesis and epithelial cell growth. Nature. 2006;441:362-5.

43. Gilbert S, Loranger A, Lavoie JN, Marceau N. Cytoskeleton keratin regulation of FasR signaling through modulation of actin/ezrin interplay at lipid rafts in hepatocytes. Apoptosis. 2012:17:880-94.

44. Snider NT, Omary MB. Post-translational modifications of intermediate filament proteins: mechanisms and functions. Nat Rev Mol Cell Biol. 2014;15:163-77.

45. Toivola DM, Boor P, Alam C, Strnad P. Keratins in health and disease. Curr Opin Cell Biol. 2015;32:73-81

46. Guldiken N, Zhou Q, Kucukoglu O, Rehm M, Levada K, Gross A, et al. Human keratin 8 variants promote mouse acetaminophen hepatotoxicity coupled with JNK activation and protein adduct formation. Hepatology. 2015. doi:10.1002/hep.27891

47. Fontana RJ, Hayashi PH, Gu J, Reddy KR, Barnhart H, Watkins PB, et al. Idiosyncratic drug-induced liver injury is associated with substantial morbidity and mortality within 6 months from onset. Gastroenterology. 2014;147:96-108 